\title{
LCD vs. E-ink: An Analysis of the Reading Behavior
}

\author{
Eva Siegenthaler \\ Swiss Distance University of Applied \\ Sciences \\ Michael Wyss
University of Bern
}

\author{
Laura Schmid \\ University of Bern
}

Pascal Wurtz

GfK Switzerland AG, SirValUse, Biel

\begin{abstract}
Electronic books (e-book) are an interesting option compared to classic paper books. Most e-reading devices of the first generation were based on e-ink technology. With the appearance of the Apple iPad on the market, TFT-LCDs became important in the field of e-reading. Both technologies have advantages and disadvantages but the question remains whether one or the other technology is better for reading. In the present study we analyzed and compared reading behavior when reading on e-inkreader (e-ink displays) and on tablets (TFT-LCDs) as measured by eye-tracking. The results suggest that the reading behavior on tablets is indeed very similar to the reading behavior on e-ink-reader. Participants showed no difference in fixation duration. Significant differences in reading speed and in the proportion of regressive saccades suggest that tablets, under special artificial light conditions, may even provide better legibility.
\end{abstract}

\section{Keywords: e-reading, reading, tablet, e-ink reader, eye movements}

\section{Introduction}

Electronic books (e-books) have become an important part on the book market. Advantages like a storage function, the possibility of adjusting font size or searching for keywords make e-books an interesting advancement of the classic paper book. An e-book can be defined as the digitized copy of a printed book, or an electronic book that is available in a digital format or a text in a digital format. E-publishing arised in the early 1970s (Ardito, 2000). Several companies launched e-reading devices like the Newton or the Palm Pilot. The new generation of e-readers includes, among others, the Sony reader, the Amazon Kindle or the Barnes \& Noble Nook Reader. This generation of e-readers is equipped with e-ink display technology. E-ink technology has several advan- tages: The battery life is astounding. For example the new Kindle reader gets up to a month of battery life. Another advantage is that they can be used outside without glare. E-ink displays look more like printed-paper than any other display does. Their technology is based on tiny microcapsules, with a diameter in the size of a human hair. Each microcapsule contains positively charged white particles and negatively charged black particles suspended in a clear fluid. When an electric field is applied, the white particles move to the top of the microcapsule where they become visible to the user. This makes the surface appear white at that spot. At the same time, the black particles are at the bottom of the microcapsules where they are not visible. By reversing the electric field, the black particles appear at the top of the capsule, which now makes the surface appear dark at that spot ("E Ink: Technology", 2011). Some of the new e- 
Journal of Eye Movement Research

5,(3):5, 1-7

ink-readers are equipped with touch screen technology.

This often goes along with a more glare-proned screen ("cnet reviews", 2010).

With the launch of the Apple iPad in April 2010 the tablet became popular as an e-reading device. These ereading devices are based on TFT-LCDs (Thin Film Transitor-Liquid Crystal Displays), which - in contrast to e-ink displays - are active displays. A LCD is a thin, flat electronic visual display that uses the light modulating properties of liquid crystals (LCs). Each pixel of an LCD typically consists of a layer of molecules aligned between two transparent electrodes, and two polarizing filters, the axes of transmission of which are (in most of the cases) perpendicular to each other ("bit-tech.net", 2011). While e-ink readers are limited for reading, tablets are small computers and they are conceptualized for everything else. This is also the big advantage of tablets, they are not just a replacement for a book, they are multifunctional devices which can be used for communication, organization or leisure activities.

Along with the different screen technologies both devices have specific characteristics, i.e., battery life, storage capacity, user interface or screen size. Both e-inkreader and tablets have become everyday technology and it can be expected that they will become even more common in the next years. If one of these technologies will become prevalent for reading in the future is unknown and is likely depending on their legibility and usability (Siegenthaler, Wurtz, \& Groner, 2010; Siegenthaler et al., 2011). Beside new possibilities like for example searching for text, increasing or decreasing font size, bookmark, annotation functions or the function for linking to other documents, the main function still is reading and the question remains whether reading behavior is affected by the screen technology. The discussion whether e-reader with e-ink technology or tablets with LCD-technology are better for reading is emotional and scientific evidence is sparse. Many users have the conventional wisdom that e-ink displays, which look similar to paper, are better for reading ("Reflective LCD vs. eink? - MobileRead Forums", 2011). In user forums about mobile reading, there are many statements about the advantages of e-ink compared to LCDs, like the following example show: "E-INK is better for your eyes as it looks exactly like a paper book. Human eye sees printed material better than it sees material that is on an LCD. Reading on E-ink with a light on the screen (at night) is better than TFT..." ("Reflective LCD vs. e-ink? - MobileRead Forums", 2011). Research departments of big
Siegenthaler, E., Wyss, M., Schmid, L. \& Wurtz, P., (2012) LCD vs. E-ink: An Analysis of the Reading Behavior companies report inconsistent results: E-ink producer postulate that e-ink technology is better for reading, while tablet producer do not see any disadvantages when reading on tablets (Carnoy, 2010). For example William Lynch, Barnes \& Noble's CEO said about the reading on Nook Color screen "the company had done extensive research on displays and discovered that eyestrain with LCDs was not the huge issue many people were making it out to be"(Carnoy, 2010). But there is no scientific evidence for this statement.

Results from past studies about reading on computer displays (Visual Display Units) show that compared to reading from paper, reading from Visual Display Units is less accurate, slower, more fatiguing and less liked by readers (Creed et al., 1987; Dillon, 1992; Gould \& Grischkowsky, 1884; Mayes et al., 2001). As mentioned before new electronic reading devices feature new display technologies. Displays based on e-ink technology or new LCDs are different and results from previous studies cannot be transferred one to one on new reading devices. Previous studies about reading on e-ink-readers show that the reading behaviour on e-ink-readers is indeed very similar to the reading behaviour on print (Siegenthaler et al., 2011). Siegenthaler et al. (2011) showed that participants shared similar proportion of regressive saccades while reading on e-ink-readers and print. Moreover results suggested that e-readers, in some situations, may even provide better legibility (Siegenthaler et al., 2011). Nielsen (2010) compared reading on an e-ink-reader (Kindle), on a Tablet (Apple iPad) and on a classic paper book by experimenting on himself. He found that reading on the e-ink reader was $10.7 \%$ slower than reading on a classic paper book. Reading on a tablet was $6.2 \%$ slower than reading on a classic paper book (Nielsen, 2010). Wurtz, Siegenthaler \& Bergamin (2010) compared e-inkreaders and tablets with TFT-LCDs for reading over extended period of time (several hours). They measured visual fatigue (with subjective and objective measures) every hour and found no difference in visual fatigue when reading over extended time (Wurtz et al., 2010). They concluded that compared to visual display units of the past, both e-ink-reader and tablets are good for reading over extended time.

In the present study we want to evaluate and compare reading behavior on e-ink-reader and on tablets (LCDs) as measured by eye tracking. If reading on e-ink displays is not similar to reading on LCDs, then differences in eye movement patterns (e.g., progressive- and regressive 
Journal of Eye Movement Research

5,(3):1, 1-7

saccades, fixations) and in reading performance (e.g., reading speed) should be found.

\section{Method}

\section{Participants}

Twelve participants ( 6 female) were tested. Mean age was 23 years with a range from 20 to 26 years. The participants were selected as naive e-reader-/tablet-user with no previous experience with these devices. Properties like subjective media-experience and subjective reading-skills were balanced in the selection of participants. All participants reported normal or corrected to normal vision. Participants gave written informed consent to prior to participation. The study was performed in accordance with the latest declaration of Helsinki.

\section{Apparatus}

Eye movements were recorded with an infrared-video eyetracking-device (X120 Eye Tracker, Tobii Technology, Danderyd, Sweden). The system has a sampling rate of $120 \mathrm{~Hz}$ and spatial tracking accuracy of approximately 0.5 degrees of visual angle (largely depending on calibration quality). Because of system requirements of the eyetracking setup participants were seated on a chair at a fixed distance of approximately $60 \mathrm{~cm}$ from the eyetracker and stimulus. Before tracking participants were ask to make sure if they can read the text within the fixed distance. Font size was constant $(3 \mathrm{~mm})$. Movements of the head were allowed within a virtual box of
Siegenthaler, E., Wyss, M., Schmid, L. \& Wurtz, P., (2012)

LCD vs. E-ink: An Analysis of the Reading Behavior approximately $30 \times 20 \times 30 \mathrm{~cm}$. The experiment took place in constant artificial light conditions with indirect ceiling light and without direct sunlight. The reading devices (see Figure 1) used, were two e-reading devices with eInk (Sony e-reader Model PRS-600 and Model PRS-505) and a Tablet with backlit LED-Screen (Apple iPad, first generation). For all devices the luminance $(\mathrm{cd} / \mathrm{m} 2)$ of dark font (LF) and light background (LB) was measured using a Luxmeter (Minolta LS-110). Technical specifications of the reading devices are shown in Table 1. Background luminance on the iPad was kept constant. Standard software for reading was used (iBook for iPad, Sony reader software for PRS-505 and PRS-600). Words on each device were equal (300 words per section). Text format was in the ePub-format.

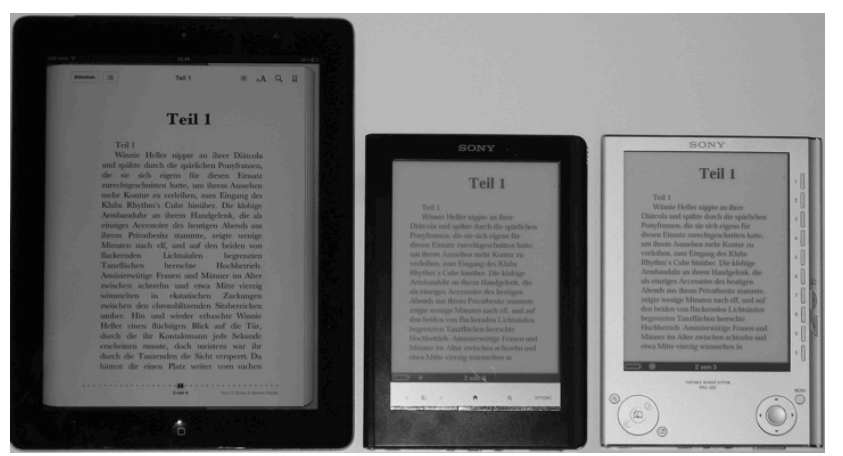

Figure 1.Apple iPad, first generation, Sony Reader PRS-600 and Sony Reader PRS-505 (from left to right).

Table 1

Device Specifications.

\begin{tabular}{ccccccc}
\hline Reading Device & Font size in mm & $\begin{array}{c}\text { Font size in } \\
\text { degree (visual } \\
\text { angle) }\end{array}$ & Monitor size & device size & weight & resolution \\
\hline Apple iPad & $3-14 \mathrm{~mm}$ & $0.286-1.337$ & $891 \times 148 \mathrm{~mm}$ & $\begin{array}{c}242.8 \times 189.7 \times \\
13.4 \mathrm{~mm}\end{array}$ & $730 \mathrm{~g}$ & $166 \mathrm{dpi}$ \\
\hline Sony PRS-505 & $2-6 \mathrm{~mm}$ & $0.191-0.573$ & $90.6 \times 122.4 \mathrm{~mm}$ & $\begin{array}{c}175 \times 122 \times \\
8 \mathrm{~mm}\end{array}$ & $260 \mathrm{~g}$ & $170 \mathrm{dpi}$ \\
\hline Sony PRS-600 & $3-4 \mathrm{~mm}$ & $0.286-0.382$ & $90 \times 120 \mathrm{~mm}$ & $\begin{array}{c}184 \times 120.5 \mathrm{x} \\
9.9 \mathrm{~mm}\end{array}$ & $230 \mathrm{~g}$ & $166 \mathrm{dpi}$ \\
\hline
\end{tabular}

\section{Stimuli and Experimental Procedure}

The experiment took place in a closed experimental room at University of Bern. First Participants were given written instructions for the experiment. If they had no further questions participants were seated in front of the eye tracking system and the calibration was started. If calibration data was sufficient the test was started. Text 
Journal of Eye Movement Research

$5,(3): 5,1-7$

material was a novel (Roth, 2008) in German language, which was the native language of all participants. Every participant read two pages (with a total of 300 words) from the novel on each device. The sequence of the reading devices was counter balanced to control for possible order effects. After reading, participants were asked questions about legibility of the devices. They had to give marks for the legibility (on a Likert-scale from 1-6) and they had to choose their favourite device for reading. In a second phase participants had to perform exercises on the reading devices (cf. Siegenthaler, Wurtz, Schmid, et al., 2010). After this performance test, the second legibility test was performed, which was identical to the first legibility test with the exception of different text segments. After the second legibility test, participants were interviewed again and asked to give their overall subjective judgments. The design of the experiment was withinsubject, i.e. each participant was tested with each device, therefore reducing effects of individual differences.

\section{Results}

\section{Reading behavior}

Reading speed. Reading speed was measured in number of characters per minute. Reading time was calculated on the basis of time codes from the eye movement recordings. The time stamps for starting/stopping reading and page-turns were coded offline. Statistical analysis was performed using F-statistics based on a $3 \times 2$ repeated measures ANOVA with the within factors reading device (Sony PRS-505, Sony PRS-600, iPad) and session (first and second legibility test). Reading speed differed significantly between reading devices $(\mathrm{F}(2,10)=6.922$, $\mathrm{p}<$ $.05)$ and sessions $(\mathrm{F}(1,10)=11.121, \mathrm{p}<.05)$. Table 2 shows mean and standard deviation of the characters read per minute.

Table 2

Number of characters per minute.

\begin{tabular}{cccc}
\hline $\begin{array}{c}\text { Reading } \\
\text { Device }\end{array}$ & Session 1 & \multicolumn{2}{c}{ Session 2 } \\
\hline & $\begin{array}{c}\text { Mean } \\
\text { number of } \\
\text { characters } \\
\text { per minute }\end{array}$ & SD & $\begin{array}{c}\text { Mean } \\
\text { number of } \\
\text { characters } \\
\text { per minute }\end{array}$ \\
\hline
\end{tabular}

Siegenthaler, E., Wyss, M., Schmid, L. \& Wurtz, P., (2012)

LCD vs. E-ink: An Analysis of the Reading Behavior

\begin{tabular}{ccccc}
$\begin{array}{c}\text { Sony PRS- } \\
505\end{array}$ & 1122 & 191 & 1183 & 262 \\
$\begin{array}{c}\text { Sony PRS- } \\
600\end{array}$ & 1041 & 226 & 1117 & 240 \\
\begin{tabular}{l} 
iPad \\
\hline
\end{tabular} & 1133 & 213 & 1266 & 325 \\
\hline
\end{tabular}

Fixation Duration. No significant difference in fixation duration was found between reading devices $(\mathrm{F}(2$, $10)=2.473, \mathrm{p}=.107)$ and sessions $(\mathrm{F}(1,10)=.740, \mathrm{p}=$ $.408)$.

Regressive saccades. Saccades were computed based on the positional information of consecutive fixations, saccades (the direction and distance between two consecutive fixations). Two types of saccades were distinguished: rightward "progressive" saccades (positive $\mathrm{x}$ vector) and leftward "regressive" saccades (negative $\mathrm{x}$ vector). Leftward saccades exceeding more than $75 \%$ of line length were classified as line sweeps. Large saccades exceeding the dimensions of the reading device were considered as artefacts and excluded from analysis; resulting in excluding $1 \%$ of saccades. Table 3 shows the percentage of saccade types. The 2 x 5 - factorial analysis of variance revealed a significant main effect of reading device on the percentage of regressive saccades $(\mathrm{F}(2$, $10)=21.102, p<.001)$. Percentage of regressive saccades did not differ between the two sessions $(F(1,10)=$ $.139, \mathrm{p}=.716$.). No interaction between device and session was found $(\mathrm{F}(1,10)=1.752, \mathrm{p}=.197)$.

Table 3

Percentage of regressive saccades.

\begin{tabular}{ccccccc}
\hline $\begin{array}{c}\text { Reading } \\
\text { Device }\end{array}$ & \multicolumn{2}{c}{ Session 1 } & \multicolumn{2}{c}{ Session 2 } \\
\hline & M & SD & $\begin{array}{c}\text { Significant } \\
\text { difference } \\
\text { to }\end{array}$ & M & SD & $\begin{array}{c}\text { Significant } \\
\text { difference } \\
\text { to }\end{array}$ \\
\hline $\begin{array}{c}\text { Sony PRS- } \\
505\end{array}$ & 22.8 & 6.2 & iPad & 23.4 & 1.2 & $\mathrm{iPad}$ \\
$\begin{array}{c}\text { Sony PRS- } \\
600\end{array}$ & 24.7 & 4.8 & iPad & 22.5 & 1.1 & $\mathrm{iPad}$ \\
iPad & 17.2 & 6.1 & $\begin{array}{c}\text { Sony PRS- } \\
\text { 505; Sony } \\
\text { PRS-600 }\end{array}$ & 17.4 & 0.5 & $\begin{array}{c}\text { Sony PRS- } \\
505 ; \text { Sony } \\
\text { PRS-600 }\end{array}$ \\
\hline
\end{tabular}

Contrasts. We measured the luminance $(\mathrm{cd} / \mathrm{m} 2)$ of font (IF) and of background (IB), using a luminance meter (Minolta LS-110). Based on these measurements, we computed the Weber contrasts between font and 
Journal of Eye Movement Research

$5,(3): 1,1-7$

background according to the following formula: $[\mathrm{CW}=(\mathrm{IF}-\mathrm{IB}) / \mathrm{IB}]$. Table 4 shows the results of the measurement and the calculation. Measurements were taken under constant surround illumination with artificial light conditions (no daylight). Due to the negative polarity (black font against white background), the contrast values are negative.

Table 4

Weber contrasts.

\begin{tabular}{cccc}
\hline Reading Device & $\begin{array}{c}\text { Font lumi- } \\
\text { nance }\left(\mathbf{I}_{\mathbf{F}}\right)\end{array}$ & $\begin{array}{c}\text { Background } \\
\text { luminance } \\
\left(\mathbf{I}_{\mathbf{B}}\right)\end{array}$ & $\begin{array}{c}\text { Weber con- } \\
\text { trast }\left[\mathbf{C}_{\mathbf{W}}=\right. \\
\left.\left(\mathbf{I}_{\mathbf{F}}-\mathbf{I}_{\mathbf{B}}\right) / \mathbf{I}_{\mathbf{B}}\right]\end{array}$ \\
\hline Apple iPad & 3.01 & 120 & -0.975 \\
Sony PRS-505 & 8.95 & 35.5 & -0.745 \\
Sony PRS-600 & 8 & 34.2 & -0.767 \\
\hline Weber-contrasts $\left(C_{W}\right)$ of black font $\left(I_{F}\right)$ on white background \\
$\left(I_{B}\right) .\left(I\right.$... Luminance in $\left.\mathrm{cd} / \mathrm{m}^{2}\right)$.
\end{tabular}

\section{Subjective Data}

Subjective legibility rating. Subjective legibility was rated on a 6 point Likert-scale $(1=$ very bad to $6=$ very good). Table 5 shows means and standard deviations of the ratings. Because of unequal variances, Friedman-tests (using $\mathrm{x}^{2}$ statistics) were employed (post-hoc tests were calculated using Wilcoxon tests). No significant differences were found in session $1\left(\mathrm{x}^{2}(2, \mathrm{~N}=12)=2.773, \mathrm{p}=\right.$ .250). In session 2 significant differences in subjective legibility ratings were found $\left(\mathrm{x}^{2}(2, \mathrm{~N}=12)=6.350, \mathrm{p}<\right.$ .05.).

Table 5

Subjective legibility ratings.

\begin{tabular}{ccccc}
\hline $\begin{array}{c}\text { Reading } \\
\text { Device }\end{array}$ & \multicolumn{2}{c}{ Session 1 } & \multicolumn{2}{c}{ Session 2 } \\
\hline & $\mathrm{M}$ & $\mathrm{SD}$ & $\mathrm{M}$ & $\mathrm{SD}$ \\
\hline $\begin{array}{c}\text { Sony PRS- } \\
505\end{array}$ & 4.95 & 0.68 & 4.41 & 1.24 \\
$\begin{array}{c}\text { Sony PRS- } \\
\quad 600\end{array}$ & 4.12 & 1.2 & 4.25 & 1.09 \\
$\mathrm{iPad}$ & 4.95 & 0.81 & 5.25 & 0.54 \\
\hline
\end{tabular}

Additionally, subjects had to elect their favorite device for reading. Figure 2 shows the distribution of favorites for reading in the two sessions.
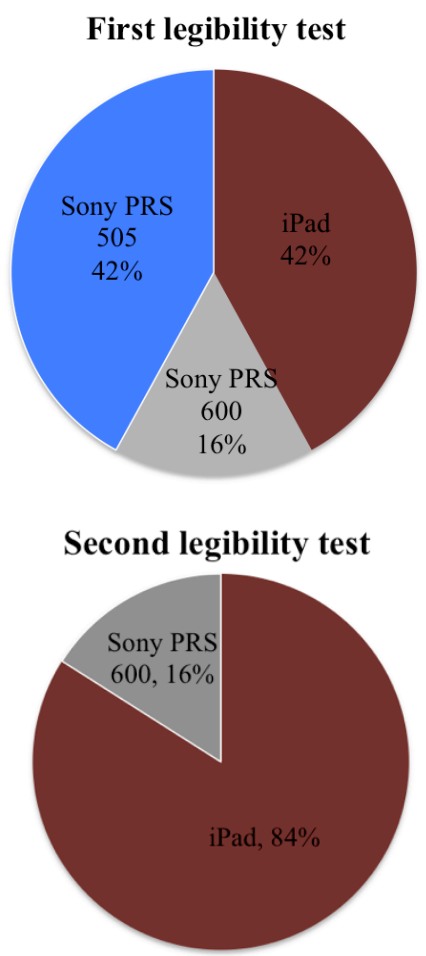

Figure 2. Distribution of favorites for reading in the two sessions.

\section{Discussion}

Overall the results suggest that the legibility of the current e-reader generation is fairly good. The analysis of eye movement data shows that reading behaviour on LCDs (tablets) is very similar to the reading behaviour on e-ink displays. There was no significant difference in fixation durations which gives evidence that participants didn't have more difficulties with reading on LCDs compared to e-ink displays. Fixation duration can be used as a measure of legibility. During fixations, when the eye stands still for a short period of time, visual information is extracted and cognitive processing is applied (Rayner \& Pollatsek, 1989). Indeed there is an advantage for the LCD; significant difference in reading speed was found, participants read faster on the tablet than on the two eink-readers. This is partially in consent with Nielsens' report (Nielsen, 2010). He found that reading on the e-ink reader was $10.7 \%$ slower than reading on a classic paper book. Reading on a tablet was $6.2 \%$ slower than reading on a classic paper book (Nielsen, 2010). In contradiction Siegenthaler et al. (2011) found no difference in reading 
speed between reading on e-ink devices and reading on a classic paper book (Siegenthaler et al., 2011). Furthermore, participants did significantly less regressive saccades when reading on tablets. If a reader does more regressive saccades, it can be taken as empirical evidence that the reader has problems in extracting visual and/or linguistic information. Since the same text was read, counterbalanced over readers and devices, we interpret more regressive saccades as being caused by lower legibility. Our results show that participants did significantly more regressive saccades when reading from an e-ink display compared with the LCD (tablet). The question arises in what respect LCDs show better legibility than eink displays. The result could be caused by the different screen size. The Apple iPad which has a 148 x $196 \mathrm{~mm}$ display is bigger than the two Sony e-ink displays (PRS505/PRS-600: 90 x $122.4 \mathrm{~mm}$ ). Earlier studies show heterogeneous results of the influence of line length on legibility (Dyson, 2004; Shahikh, 2007). Font size was constant $(3 \mathrm{~mm})$ that means that number of characters per line is caused by line length and not confounded with font size. The devices were selected for the experiment because they were the most popular devices on the Swiss market at this time. In a future experiment we will test a TFT-LCD and an e-ink display with the same screen size for make out the effect of display size. Another explanation for the result is that the percentage of regressive saccades is related to contrast. Under artificial (low light) conditions LCDs have a better contrast (CW -38.87) than e-ink displays ( $\mathrm{CW}-2.97 /-3.275)$. If the result is caused by the contrast we could conclude that under specific artificial light conditions LCDs have a better legibility than e-ink displays. The mean percentage of regressive saccades over all devices (17\% iPad; 22\% PRS-505; 23\% PRS-600) is rather high. According to Findlay (Findlay \& Gilchrist, 2003) 18\% regressive saccades is normal when reading a scientific text. The text in the experiment was not scientific. The rather high rate of regressive saccades could be explained on one hand by the laboratory setting and the relatively large reading distance to the eye tracker or by the effort of participants to perform as good as possible in the experiment.

An interesting fact seems to be that we did not find any difference in the reading behavior between the Sony PRS-505 and the Sony PRS-600. The new Sony PRS-600 is equipped with a touch-screen. This often goes along with a more glare-proned screen. The results show a tendency that the touch-screen (Sony PRS-600) is some- what less readable but because of no statistical difference, we can say that the touch-screen on e-ink devices does not reduce legibility of the device.

Subjective interview data revealed that participants changed their opinion in the second session after having made some experiences with the devices. While participants judged the legibility of the iPad and the Sony PRS505 as equal (4.95) in the first session, the legibility of the iPad was judged better (5.25) and the legibility of the Sony PRS-505 was judged worse (4.41) in the second session. This fact shows how important it is to use different methods (subjective and objective methods) in $\mathrm{Hu}-$ man-Computer-Research. The result demonstrates also that legibility judgments are influenced by the user experience with the devices.

As we know from earlier studies the reading process when reading on an e-ink-reader is very similar to the reading process when reading a classic paper book (Siegenthaler et al., 2011). Since the results in the present study show that reading on a tablet is not worse than reading on an e-ink-reader we can conclude that reading on a tablet is under artificial light conditions not worse than reading on a classic paper book.

\section{References}

Ardito, S. (2000). Electronic Books: To E" or not to E“; that is the question (No. 4). Searcher. Ardito Information \& Research. Inc. Retrieved June 15, 2011, from http:/www.infotoday.com/searcher/apr00/ardito.htm

Carnoy, D. (2010). LCD vs. e-ink: The eyestrain debate | Fully Equipped - CNET Reviews. Retrieved June 15, 2011, from http://reviews.cnet.com/830118438 7$\underline{20021227-82 . h t m l}$

Creed A., Dennis I., \& Newstead S. (1987). Proofreading on VDUs. Behaviour \& Information Technology, 6(1), 3-13.

Dillon, A. (1992). Reading from paper versus screens: a critical review of the empirical literature. Ergonomics, 35(10), 1297. doi:10.1080/00140139208967394

Dyson, M. C. (2004). How physical text layout affects reading from screen. Behaviour \& Information Technology, 23(6), 377-393.

E Ink: Technology. (2011). e ink. Retrieved March 1, 2011, von http://www.eink.com/technology.html 
Journal of Eye Movement Research

$5,(3): 1,1-7$

Findlay J.M., \& Gilchrist I.D. (2003). Active Vision - The Psychology of Looking and Seeing. Oxford University Press.

Gould D., \& Grischkowsky, N. (1884). Doing the same work with hard copy and with cathode-ray tube (CRT) computer terminals. Human Factors, 26(3), 323-337.

How CRT and LCD monitors work | bit-tech.net. (2011). Retrieved July 20, 2011, from http://www.bittech.net/hardware/2006/03/20/how_crt and lcd monitors work $/ 3$

Mayes, D. K., Sims, V. K., \& Koonce, J. M. (2001). Comprehension and workload differences for VDT and paper-based reading. International Journal of Industrial Ergonomics, 28(6), 36-378.

Nielsen, J. (2010). iPad and Kindle Reading Speeds (Jakob Nielsen's Alertbox). Retrieved June 26, 2011, from http://www.useit.com/alertbox/ipadkindlereading.html

Rayner, K., \& Pollatsek, A. (1989). The psychology of reading. Englewood Cliffs: Prentice-Hall.

Reflective LCD vs. e-ink? - MobileRead Forums. (2011). Retrieved August 12, 2011, from http://www.mobileread.com/forums/showthread.php?t $=76207$

Roth, S. (2008). Querschläger. Hamburg, Germany: Hoffmann und Campe Verlag.

Shahikh Dawn A. (2007). The Effects of Line Length on Reading Online News. Usability News, 7(2).

Siegenthaler, E., Wurtz, P., \& Groner, R. (2010). Improving the Usability of E-Book Readers. Journal of Usability Studies, 6(1), 25-38.

Siegenthaler, E., Wurtz, P., Bergamin, P., \& Groner, R. (2011). Comparing reading processes on e-ink displays and print. Displays, 32 (5), 268-273. http://dx.doi.org/10.1016/j.displa.2011.05.005.

Siegenthaler, E., Wurtz, P., Schmid, L., \& Bergamin, P. (2010). The effects of touch screen technology on the usability of e-reading devices. International Journal of Usability Studies, under review.

Wurtz, P., Siegenthaler, E., Bochud, Y. \& Bergamin, P. (2010). Reading on LCD versus e-Ink displays: Effects on fatigue and visual strain. Ophthalmic and Physiological Optics, under review. 